\title{
Tinnitusrelief Device in Treatment of Bothersome Tinnitus: Preliminary Experience in Private Setting
}

\author{
Sachin Goel* and Soniya Gupta \\ Innoflaps Remedy Pvt. Ltd., New Rajdhani Enclave, India
}

Submission: December 24, 2016; Published: March 22, 2017

*Corresponding author: Sachin Goel, Department of ENT, PGIMSR \& ESIC Model hospital, Basai darapur, New Delhi, India, Tel: 9891014815;

Email: dr.sachingoel@gmail.com

Keywords: Tinnitus; Tinnitus matching; Tinnitus retraining therapy

\section{Introduction}

Tinnitusrelief is a portable, noninvasive, handheld, rechargeable device which provides long term relief for tinnitus. Using the diagnose feature after identification of tinnitus frequency and intensity, Tinnitus Relief provides 22 customized sounds including narrow band and white band noises, in frequency range of $100 \mathrm{~Hz}-16 \mathrm{KHz}$ to cause habituation and neuromodulation providing relief in both recent onset and persistent bothersome tinnitus. The principle of the device design aligns with that of TRT (Tinnitus Retraining Therapy) and Neuromodulation.

As reported by Henry et al. [1], tinnitus is experienced by 40 to 50 million individuals and the tinnitus is so problematic as to be debilitating for about 2.5 million of these persons [2]. Debilitating tinnitus can impact a person emotionally and can affect concentration and sleep. Depending on the severity of these effects, tinnitus can further affect job performance, relationships, and social functioning. Because of our increasingly noisy society, the prevalence of tinnitus is expected to increase [3]. Physicians, audiologists, and counselors are thus faced with a rising number of patients with tinnitus as their primary complaint. A handful of treatment methods have gained wide acceptance on reducing the effect of tinnitus on the patient's quality of life. These are generally regarded as viable treatment option for individuals with clinically significant tinnitus. Tinnitus retraining therapy (TRT) uses non-psychiatric tinnitus-specific educational counseling and sound therapy in a habituation-based protocol; and tinnitus maskings are two such methods.

The aim of this case series was to explore whether a newer portable handheld device "Tinnitus Relief" will be effective in providing relief in patients with both recent onset and persistent tinnitus due to multiple etiologies.

\section{Materials and Methods}

The present case series was carried out over a two months' period from March 2016 to April 2016 in the private clinic setting, New Delhi. Oral and written consent was taken from all participants. A Total of 20 patients visiting the private otorhinolaryngology clinic between March 2016 to April 2016 with clinical history of bothersome tinnitus were selected for the study. All subjects met the following criteria based on a subjective clinical interview:

a. History of recent onset or persistent tinnitus either primary or secondary.

b. No history of psychiatric illness or seizures.

All subjects underwent audiologic tests including puretone audiometry, tinnitogram, impedance audiometry, auditory brainstem response, and otoacoustic emission. Laboratory tests included complete blood count, blood chemistry, serum lipid profile, and thyroid function test. A total of 20 patients who met these criteria were enrolled. The patients underwent tinnitus matching with conventional audiometer on day 1 and rematching was done with tinnitus relief device on day 3 by different investigators with blinding the results of initial matching. Following matching a test tone was presented to patient's diseased ear for one minute and time was noted till patient no longer hears the tinnitus.

These participants were grouped into two groups of 10 participants in each group. Group 1 included of 10 participants and they were introduced with Tinnitus Relief device for tinnitus therapy and the other Group 2 included of 10 participants who underwent conventional therapy with audiometer. THI scores were obtained by the participants of both groups and 
comparison was done after 2 months. Sound therapy was given for 90 minutes' daily duration using Tinnitus Relief in group 1 and conventional audiometer in group 2. THI scores were obtained after every month of sound therapy and compared in both groups and with initial THI scores. Statistical analysis was employed for evaluating the results including pre-and post THI score in Group 1 and Group 2.

\section{Results}

Table 1: Data of the participants.

\begin{tabular}{|c|c|c|c|c|c|c|c|}
\hline \multicolumn{4}{|c|}{ G1 with Tinnitus Device } & \multicolumn{4}{|c|}{ G2 without Tinnitus Device } \\
\hline Patient & Age & Gender & Severity & Patient & Age & Gender & Severity \\
\hline $\mathrm{P} 1$ & 65 & Male & Catastrophic & $\mathrm{P} 1$ & 63 & Male & Catastrophic \\
\hline $\mathrm{P} 2$ & 68 & Female & Catastrophic & P2 & 66 & Female & Catastrophic \\
\hline P3 & 37 & Male & Sever & P3 & 38 & Male & Sever \\
\hline $\mathrm{P} 4$ & 45 & Male & Sever & $\mathrm{P} 4$ & 43 & Male & Sever \\
\hline P5 & 50 & Female & Sever & P5 & 47 & Female & Sever \\
\hline P6 & 33 & Female & Sever & P6 & 34 & Female & Sever \\
\hline P7 & 44 & Male & Moderate & P7 & 45 & Male & Moderate \\
\hline P8 & 37 & Male & Moderate & P8 & 36 & Male & Moderate \\
\hline P9 & 41 & Female & Moderate & P9 & 42 & Female & Moderate \\
\hline P10 & 51 & Female & Moderate & P10 & 54 & Female & Moderate \\
\hline
\end{tabular}

The study included 20 patients with history of tinnitus. Below is the data of the individuals participated in the present study (Table 1) (Figure 1). THI score shows 56\% improvement in participant's quality of life in Group 1 as compare to Group 2. This study shows that after treatment with Tinnitus Relief Device, patients from group 1 achieved a successful outcome on completing treatment. The criterion for success was chosen to avoid any possibility of placebo effect. According to Duckert and Rees [4], the success rate is also far above the highest estimated placebo effect for tinnitus treatment, in continuation these authors stated that subsequent studies on this cohort of patients will look to see how this improvement is maintained over a longer period (Figure 2).

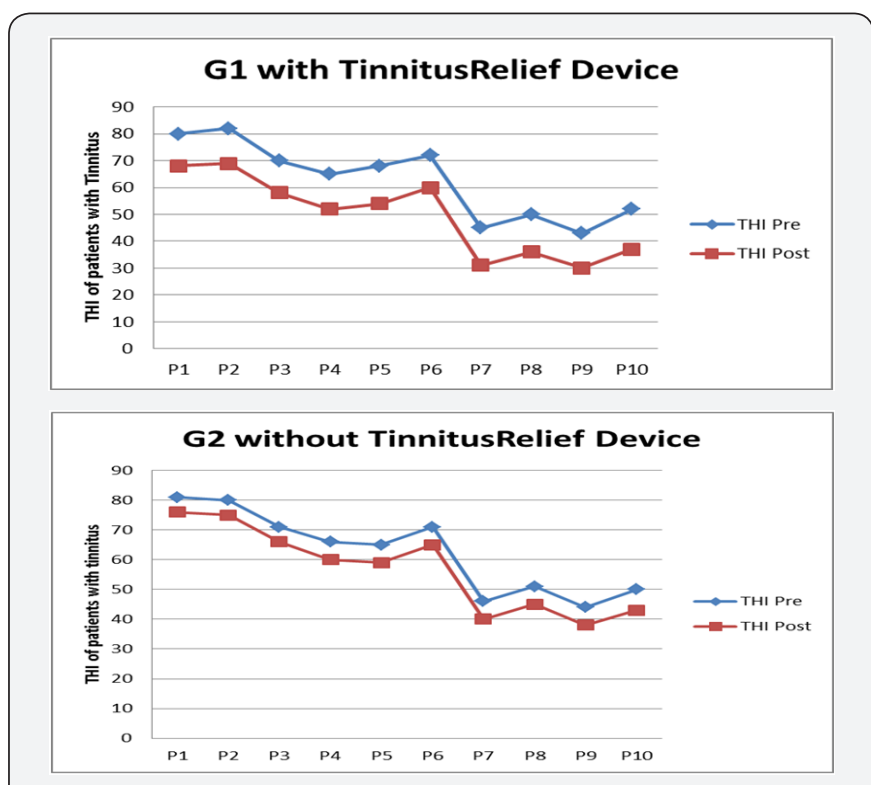

Figure 1: THI scores of Group 1 and Group 2. 
if any further comparison done between Tinnitus Relief device and other similar devices.

\section{Declaration of Conflicting Interests}

The author(s) declared no potential conflicts of interest with respect to the research, authorship, and/or publication of this article.

\section{Funding}

The author(s) received no financial support for the research, authorship, and/or publication of this article.

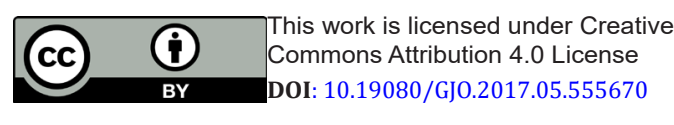

\section{References}

1. Henry JA, Griest S, Zaugg TL, Thielman E, Kaelin C, et al. (2015) Tinnitus and Hearing Survey: A Screening Tool to Differentiate Bothersome Tinnitus from Hearing Difficulties. Am J Audiol 24(1): 66-77.

2. Davis A, Refaie AE (2000) Epidemiology of tinnitus. In R Tyler (Ed.), Tinnitus handbook. San Diego, Singular, CA, USA, p. 1-23.

3. Coles R (1998) Therapeutic blind alleys. In JA Vernon (Ed.), Tinnitus treatment and relief. Needham Heights, Allyn \& Bacon, MA, USA, p. 8-19.

4. Duckert LG, Rees TS (1983) Treatment of tinnitus with intravenous lidocaine: a double-blind randomized trial. Otolaryngol Head Neck Surg 91(5): 550-555.

\section{Your next submission with Juniper Publishers will reach you the below assets}

- Quality Editorial service

- Swift Peer Review

- Reprints availability

- E-prints Service

- Manuscript Podcast for convenient understanding

- Global attainment for your research

- Manuscript accessibility in different formats

( Pdf, E-pub, Full Text, Audio)

- Unceasing customer service

Track the below URL for one-step submission https://juniperpublishers.com/online-submission.php 